\title{
PERKALIAN MATRIKS PADA GRAF RODA
}

\author{
Novita Indah Saputri, Mariatul Kiftiah, Fransiskus Fran
}

\begin{abstract}
INTISARI
Perkalian matriks pada graf adalah perkalian antara matriks ketetanggaan dari dua graf yang memiliki jumlah simpul yang sama. Matriks ketetanggaan dari suatu graf $G$ disimbolkan dengan $A(G)$. Suatu matriks disebut grafikal apabila matriks tersebut merupakan matriks simetris $(0,1)$ dengan entri pada diagonalnya adalah nol. Pada penelitian ini dibahas kondisi-kondisi perkalian matriks terkait graf roda $\left(W_{n}\right)$ yang grafikal. Berdasarkan hasil penelitian diperoleh $A\left(W_{n}\right) A\left(\overline{W_{n}}\right)$ dan $A\left(\overline{W_{n}}\right) A(G)$ tidak grafikal apabila $n \geq 4$, dengan $\overline{W_{n}}$ merupakan komplemen graf roda dan graf $G$ merupakan subgraf roda yang diperoleh dengan cara menghapus sisi yang tidak bersisian dengan simpul pusat. Selanjutnya diperoleh $A\left(W_{n}\right) A(H)$ tidak grafikal untuk seтиa $n$ dan $A\left(\overline{W_{n}}\right) A(H)$ tidak grafikal apabila $n \geq 6$, dengan graf $H$ merupakan subgraf roda yang diperoleh dengan cara menghapus sisi yang bersisian dengan simpul pusat.
\end{abstract}

Kata Kunci: matriks ketetanggaan, subgraf roda, komplemen graf roda.

\section{PENDAHULUAN}

Teori graf digunakan untuk merepresentasikan objek-objek diskrit dan hubungan antara objekobjek tersebut [1]. Graf secara geometri dinyatakan dengan beberapa titik atau simpul yang dihubungkan dengan garis atau simpul. Matriks ketetanggaan merupakan salah satu matriks yang diperoleh dari merepresentasikan suatu graf dengan cara melihat hubungan antar simpul yang ada pada suatu graf tersebut. Terdapat beberapa teori yang menerapkan konsep matriks ketetanggaan salah satunya adalah perkalian matriks pada graf. Perkalian matriks pada graf diperoleh dengan cara mengalikan dua matriks ketetanggaan dari graf yang mempunyai jumlah simpul yang sama banyak. Perkalian matriks pada graf dapat direalisasikan dalam bentuk graf apabila hasil dari perkaliannya merupakan matriks simetris $(0,1)$ dan entri pada diagonalnya adalah nol. Terdapat salah satu penelitian yang membahas tentang perkalian matriks pada sembarang graf [2]. Belum banyak penelitian yang membahas tentang perkalian matriks pada graf terutama pada graf-graf khusus. Oleh karena itu, pada penelitian ini dibahas perkalian matriks pada graf khusus yaitu graf roda.

\section{PERKALIAN MATRIKS PADA GRAF}

Perkalian matriks pada graf merupakan salah satu konsep yang dikembangkan dari teori graf dengan menggunakan matriks ketetanggaan. Sebelumnya diberikan definisi matriks ketetanggaan sebagai berikut.

Definisi 1 [3] Misalkan $G=(V, E)$ adalah graf tak berarah dengan simpul-simpul $v_{1}, v_{2}, \ldots, v_{n}$. Matriks ketetanggaan yang sesuai dengan graf $G$ adalah $A(G)=\left(a_{i j}\right)$ dengan $a_{i j}$ adalah jumlah sisi yang menghubungkan simpul $v_{i}$ ke simpul $v_{j} ; i, j=1,2, \ldots, n$.

Berdasarkan Definisi 1 maka untuk suatu graf tak berarah $(G)$ jumlah sisi yang menghubungkan simpul $v_{i}$ ke $v_{j}$ dan simpul $v_{j}$ ke $v_{i}$ pada graf $(G)$ selalu sama. Oleh karena itu, matriks ketetanggaan pada graf tak berarah merupakan matriks simetris. Suatu matriks simetris dapat dikaitkan kembali dengan graf, berikut ini diberikan Definisi 2 untuk mejelaskan kaitan dari matriks simetris pada graf. 
Definisi 2 [2] Suatu matriks simetris $(0,1)$ disebut grafikal jika untuk setiap entri pada diagonalnya adalah nol. Jika matriks $B$ adalah matriks grafikal sedemikian sehingga $B=A(G)$ untuk suatu graf $G$, maka graf $G$ disebut realisasi dari matriks grafikal $B$.

Definisi 2 dapat diterapkan dalam konsep perkalian matriks pada graf yang dalam hal ini dijelaskan pada Definisi 3 sebagai berikut.

Definisi 3 [2] Misal terdapat dua graf yaitu graf $G$ dan graf $H$ yang mempunyai himpunan simpul yang sama banyak. Graf $\Gamma$ merupakan hasil kali matriks dari $G$ dan $H$ apabila $A(G) A(H)$ grafikal dan graf $\Gamma$ merupakan realisasi dari $A(G) A(H)$.

Dari Definisi 1, Definisi 2 dan Definisi 3 diberikan contoh untuk menjelaskan perkalian matriks pada graf sebagai berikut.

Contoh 4 Diberikan graf $G$ dan graf $H$ dengan himpunan simpul yang sama yaitu $\left\{v_{1}, v_{2}, v_{3}, v_{4}\right\}$ sebagai berikut.

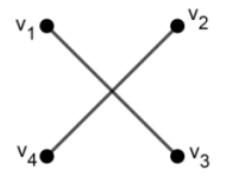

(a)

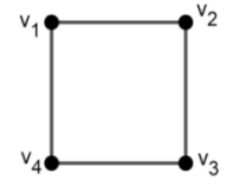

(b)

Gambar 1 (a) Graf $G$ dan (b) Graf $H$

Berdasarkan Definisi 1 diperoleh matriks ketetanggaan untuk graf $G$ dan graf $H$ seperti berikut.

$$
A(G)=\left[\begin{array}{llll}
0 & 0 & 1 & 0 \\
0 & 0 & 0 & 1 \\
1 & 0 & 0 & 0 \\
0 & 1 & 0 & 0
\end{array}\right] \text { dan } A(H)=\left[\begin{array}{llll}
0 & 1 & 0 & 1 \\
1 & 0 & 1 & 0 \\
0 & 1 & 0 & 1 \\
1 & 0 & 1 & 0
\end{array}\right]
$$

Kemudian dari $A(G)$ dan $A(H)$ diperoleh mariks $A(\sqsubseteq)$ yang merupakan hasil dari $A(G) A(H)$ sebagai berikut.

$$
A(ґ)=\left[\begin{array}{llll}
0 & 1 & 0 & 1 \\
1 & 0 & 1 & 0 \\
0 & 1 & 0 & 1 \\
1 & 0 & 1 & 0
\end{array}\right]
$$

Berdasarkan Definisi 2, dapat diketahui bahwa matriks $A(\lceil)$ merupakan matriks yang grafikal. sehingga berdasarkan Definisi 3 , diperoleh graf $\Gamma$ merupakan realisasi dari matriks $A\left(\Gamma^{\prime}\right)$ adalah sebagai berikut.

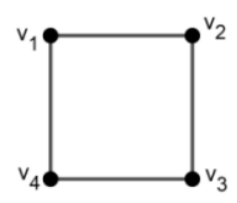

\section{Gambar 2 Graf I}

Entri diagonal pada $A(G) A(H)$ haruslah nol, untuk memastikan agar entri diagonal pada $A(G) A(H)$ adalah nol diberikan Lemma 5 dengan $\bar{G}$ adalah komplemen dari graf $G$ sebagai berikut.

Lemma 5 [2] Diberikan graf $G$ dan graf $H$ dengan himpunan simpul yang sama $\left\{v_{1}, v_{2}, \ldots, v_{n}\right\}$, entri diagonal pada $A(G) A(H)$ adalah nol jika dan hanya jika $H$ adalah subgraf dari $\bar{G}$.

\section{Bukti:}

$\Leftrightarrow$ Misal graf $H$ bukan merupakan subgraf dari $\bar{G}$, artinya terdapat sisi $e_{i}$ pada $H$ yang mempunyai simpul ujung yang sama dengan sisi $e_{j}$ pada $G$. Sehingga pada matriks ketetanggaannya terdapat baris 
ke- $i$ pada $A(G)$ yang nilai entri-entri berpadannya sama dengan nilai entri-entri pada kolom ke $-j$ pada $A(H)$ dengan $i=j$. Oleh karena itu, pada $A(G) A(H)=\left(a_{i j}\right)$ nilai $a_{i j}$ dengan $i=j$ yang diperoleh dengan menjumlahkan hasil perkalian dari entri-entri yang berpadan pada baris ke- $i$ di $A(G)$ dan kolom ke- $j$ di $A(H)$ bernilai tidak sama dengan nol. Oleh karena terbuktinya pernyataan kontraposisi tersebut, maka terbukti pula pernyataan jika entri pada diagonal $A(G) A(H)$ bernilai benar maka $H$ merupakan subgraf dari $\bar{G}$.

$(\Leftarrow)$ Diberikan suatu graf $G$ dan graf $H$ dengan graf $H$ merupakan subgraf dari graf $\bar{G}$, artinya tidak terdapat sisi yang memiliki simpul ujung yang sama pada graf $G$ dan graf $H$. Oleh karena itu, diperoleh matriks ketetanggaan $A(G)$ dan $A(H)$ dengan entri-entri yang berpadan salah satunya bernilai nol. Akibatnya pada $A(G) A(H)=\left(a_{i j}\right)$ dengan $i=j$ selalu bernilai nol.

Berdasarkan Lemma 5 diberikan contoh sebagai berikut.

Contoh 6 Diberikan graf $G$ dan graf $H$ dengan himpunan simpul yang sama yaitu $\left\{v_{1}, v_{2}, v_{3}, v_{4}\right\}$ sebagai berikut.

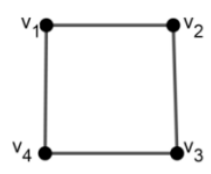

(a)

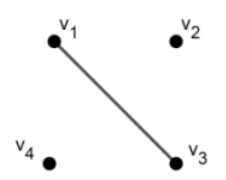

(b)

\section{Gambar 3 (a) Graf $G$ dan (b) Graf $H$}

Berdasarkan graf $G$ dan graf $H$ diperoleh matriks ketetanggaan sebagai berikut.

$$
A(G)=\left[\begin{array}{llll}
0 & 1 & 0 & 1 \\
1 & 0 & 1 & 0 \\
0 & 1 & 0 & 1 \\
1 & 0 & 1 & 0
\end{array}\right] \operatorname{dan} A(H)=\left[\begin{array}{llll}
0 & 0 & 1 & 0 \\
0 & 0 & 0 & 0 \\
1 & 0 & 0 & 0 \\
0 & 0 & 0 & 0
\end{array}\right]
$$

Berdasarkan $A(G)$ dan $A(H)$ diperoleh $A(G) A(H)$ sebagai berikut.

$$
A(G) A(H)=\left[\begin{array}{llll}
0 & 0 & 0 & 0 \\
1 & 0 & 1 & 0 \\
0 & 0 & 0 & 0 \\
1 & 0 & 1 & 0
\end{array}\right]
$$

Diperoleh entri diagonal pada $A(G) A(H)$ adalah nol.

Selanjutnya diterapkan perkalian matriks pada graf roda yang dijelaskan pada beberapa lemma dan teorema berikut. Sebelmnya diberikan Lemma tentang graf lengkap dan komplemennya dengan $v_{i} \sim{ }_{G} v_{j}$ manyatakan simpul $v_{i}$ dan simpul $v_{j}$ pada graf $G$ bertetangga sebagai berikut.

Lemma 7 Jika G merupakan graf lengkap, maka $\bar{G}$ adalah graf null.

Bukti: Diberikan $G$ merupakan graf lengkap dengan, maka $v_{i} \sim{ }_{G} v_{j}$. Oleh karena itu, himpunan sisi dari graf lengkap dari graf $G$ yaitu $E\left(K_{n}\right)$ sama dengan $E(G)$, sehingga $E\left(K_{n}\right)-E(G)=\emptyset$. Artinya $\bar{G}$ merupakan graf null.

Sebagai ilustrasi diberikan $\left(W_{3}\right)$ yang merupakan graf lengkap dan komplemennya sebagai berikut.

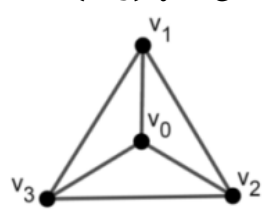

(a)

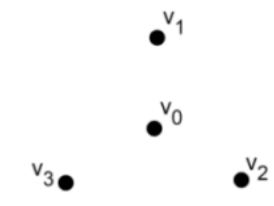

(b)

Gambar 4 (a) Graf Roda $\left(W_{3}\right)$ dan (b) Komplemen Graf Roda $\left(\overline{W_{3}}\right)$ 
Selanjutnya dibahas perkalian matriks terkait graf roda dengan $\operatorname{deg}_{G} v$ menyatakan derajat $\operatorname{simpul} v$ pada graf $G$.

Teorema 8 Diberikan graf roda $\left(W_{n}\right)$ dan komplemennya $\left(\overline{W_{n}}\right)$. Jika $n \geq 4$ maka $A\left(W_{n}\right) A\left(\overline{W_{n}}\right)$ tidak grafikal.

Bukti: Diberikan graf roda $W_{n}$ dengan $n \geq 4$, oleh karena simpul pusat $v_{0}$ terhubung ke semua simpul pada $W_{n}$, sedangkan pada $\overline{W_{n}}$ simpul pusat $v_{0}$ tidak terhubung dengan simpul manapun pada $\overline{W_{n}}$. Akibatnya matriks ketetanggaan dari $W_{n}, A\left(W_{n}\right)=\left(a_{i j}\right)$ dengan entri-entrinya $a_{1 j}$ dan $a_{i 1}$ dengan $2 \leq i, j \leq n+1$ bernilai 1 sedangkan matriks ketetanggaan dari $\overline{W_{n}}, A\left(\overline{W_{n}}\right)=\left(b_{i j}\right)$ dengan entrientrinya $b_{1 j}$ dan $b_{i 1}$ dengan $1 \leq i, j \leq n+1$ bernilai 0 . Akibatnya $A\left(W_{n}\right) A\left(\overline{W_{n}}\right)=\left(c_{i j}\right)$ dengan entri-entrinya $c_{1 j}$ dengan $2 \leq j \leq n+1$ bernilai $\operatorname{deg}_{\overline{W_{n}}} v_{i} \neq 0$ dan $c_{i 1}$ adalah 0 dengan $1 \leq i \leq n+1$ sehingga $A\left(W_{n}\right) A\left(\overline{W_{n}}\right)$ tidak grafikal.

Dari Teorema 8 diberikan contoh sebagai berikut.

Contoh 9 Diberikan graf roda $\left(W_{5}\right)$ dan graf $\left(\overline{W_{5}}\right)$ sebagai berikut.

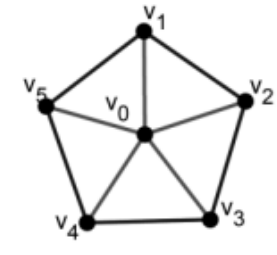

(a)

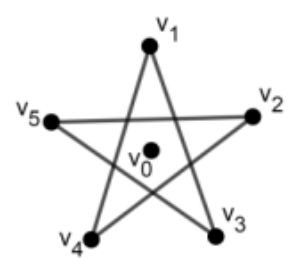

(b)

Gambar 5 (a) Graf Roda $\left(W_{5}\right)$ dan (b) Graf Roda $\left(\overline{W_{5}}\right)$

Berdasarkan graf $W_{5}$ dan $\overline{W_{5}}$ diperoleh $A(\Gamma)$ adalah $A\left(W_{5}\right) A\left(\overline{W_{5}}\right)$ sebagai berikut.

$$
A(\Gamma)=\left[\begin{array}{llllll}
0 & 2 & 2 & 2 & 2 & 2 \\
0 & 0 & 1 & 1 & 1 & 1 \\
0 & 1 & 0 & 1 & 1 & 1 \\
0 & 1 & 1 & 0 & 1 & 1 \\
0 & 1 & 1 & 1 & 0 & 1 \\
0 & 1 & 1 & 1 & 1 & 0
\end{array}\right]
$$

Diperoleh $A(\Gamma)$ merupakan matriks yang tidak gafikal sehingga tidak terdapat graf realisasi untuk $A(\Gamma)$.

Pada graf roda terdapat beberapa subgraf. Oleh karena itu, diperoleh beberapa Teorema tentang perkalian matriks dan perkalian matriks antara graf roda dengan subgraf roda yang dituangkan pada Teorema 10

Teorema $10 \mathrm{Jika} W_{n}$ merupakan graf roda dan G merupakan subgraf dari graf roda yang diperoleh dengan cara menghapus sisi yang bersisian dengan simpul pusat, maka $A\left(W_{n}\right) A(G)$ tidak grafikal untuk semua $n$.

Bukti: Diberikan graf roda $\left(W_{n}\right)$ dan dan graf $G$ yang merupakan subgraf dari graf roda yang diperoleh dengan cara menghapus sisi yang bersisian dengan simpul pusat. Berdasarkan Lemma 5 , oleh karena $G$ bukan merupakan subgraf dari $\overline{W_{n}}$ maka diperoleh entri diagonal pada $A\left(W_{n}\right) A(G)$ tidak sama dengan nol, sehingga $A\left(W_{n}\right) A(G)$ bukan merupakan matriks yang grafikal.

Diberikan contoh untuk Teorema 10 adalah sebagai berikut. 
Contoh 11 Diberikan graf roda $\left(W_{4}\right)$ dan graf $G$ yang merupakan subgraf dari $W_{4}$ sebagai berikut.

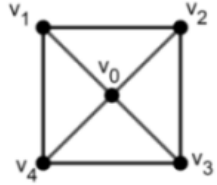

(a)

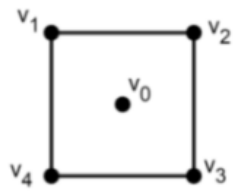

(b)

Gambar 6 (a) Graf Roda $\left(W_{4}\right)$ dan (b) Graf $G$

Berdasarkan graf $W_{4}$ dan graf $G$ diperoleh $A(\Gamma)$ adalah $A\left(W_{4}\right) A(G)$ sebagai berikut.

$$
A(\Gamma)=\left[\begin{array}{lllll}
0 & 2 & 2 & 2 & 2 \\
0 & 2 & 0 & 2 & 0 \\
0 & 0 & 2 & 0 & 2 \\
0 & 2 & 0 & 2 & 0 \\
0 & 0 & 2 & 0 & 2
\end{array}\right]
$$

Diperoleh $A(\Gamma)$ merupakan matriks yang tidak gafikal, sehingga tiak terdapat graf realisasi untuk $A(\Gamma)$.

Berdasarkan subgraf dari graf roda diperoleh beberapa Teorema terkalit Perkalian matriks antara komplemen graf roda dengan subgraf roda yang dituangkan pada Teorema 12 dan Teorema 14 sebagai berikut.

Teorema 12 Diberikan $\overline{W_{n}}$ merupakan komplemen dari graf roda dan $G$ merupakan subgraf dari graf roda yang diperoleh dengan cara menghapus sisi yang bersisian dengan simpul pusat. Jika $n \geq 6$ maka $A\left(\overline{W_{n}}\right) A(G)$ tidak grafikal.

Bukti diperoleh dengan cara yang sama seperti Teorema 8.

Diberikan contoh untuk Teorema 12 sebagai berikut.

Contoh 13 Diberikan graf roda $\left(\overline{W_{6}}\right)$ dan graf $G$ yang merupakan subgraf dari $W_{6}$ sebagai berikut.

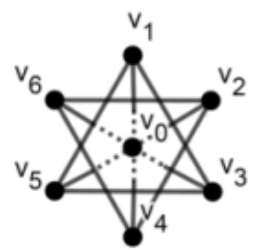

(a)

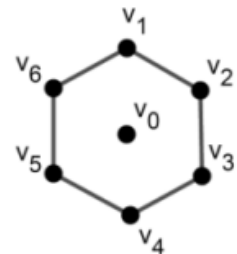

(b)

Gambar 7 (a) Graf Roda $\left(\overline{W_{6}}\right)$ dan (b) Graf $G$

Berdasarkan graf $\overline{W_{6}}$ dan graf $G$ diperoleh $A(\Gamma)$ merupakan $A\left(\overline{W_{6}}\right) A(G)$ sebagai berikut.

$$
A(\Gamma)=\left[\begin{array}{lllllll}
0 & 0 & 0 & 0 & 0 & 0 & 0 \\
0 & 0 & 1 & 1 & 2 & 1 & 1 \\
0 & 1 & 0 & 1 & 1 & 2 & 1 \\
0 & 1 & 1 & 0 & 1 & 1 & 2 \\
0 & 2 & 1 & 1 & 0 & 1 & 1 \\
0 & 1 & 2 & 1 & 1 & 0 & 1 \\
0 & 1 & 1 & 2 & 1 & 1 & 0
\end{array}\right]
$$

Diperoleh $A(\Gamma)$ merupakan matriks yang tidak grafikal, sehingga tidak terdapat graf realisasi untuk $A(\Gamma)$.

Pada subgraf roda lainnya diperoleh hasil perkalian matriks yang berbeda antara komplemen graf roda dan subgraf roda. Dalam hal ini dituangkan pada Teorema 14 sebagai berikut. 
Teorema 14 Diberikan $\overline{W_{n}}$ merupakan komplemen dari graf roda dan $G$ merupakan subgraf dari graf roda yang diperoleh dengan cara menghapus sisi yang menghubungkan simpul $v_{i}$ ke simpul $v_{j}$ dan $1 \leq i, j \leq n$. Jika $n \geq 4$ maka $A\left(\overline{W_{n}}\right) A(G)$ tidak grafikal.

Bukti diperoleh dengan cara yang sama seperti Teorema 8.

Diberikan contoh untuk Teorema 14 sebagai berikut.

Contoh 15 Diberikan graf roda $\left(\overline{W_{5}}\right)$ dan graf $G$ yang merupakan subgraf dari $W_{5}$ sebagai berikut.

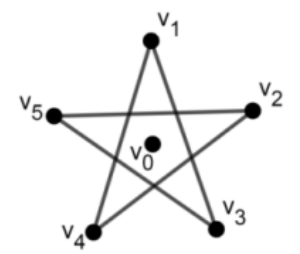

(a)

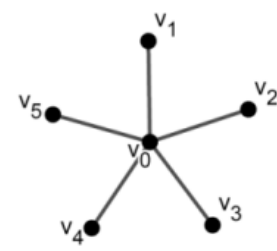

(b)

Gambar 8 (a) Graf Roda $\left(\overline{W_{5}}\right)$ dan (b) Graf $G$

Berdasarkan graf $\overline{W_{5}}$ dan graf $G$ diperoleh $A(\Gamma)$ merupakan $A\left(\overline{W_{5}}\right) A(G)$ sebagai berikut.

$$
A(\Gamma)=\left[\begin{array}{llllll}
0 & 0 & 0 & 0 & 0 & 0 \\
2 & 0 & 0 & 0 & 0 & 0 \\
2 & 0 & 0 & 0 & 0 & 0 \\
2 & 0 & 0 & 0 & 0 & 0 \\
2 & 0 & 0 & 0 & 0 & 0 \\
2 & 0 & 0 & 0 & 0 & 0
\end{array}\right]
$$

Diperoleh $A(\Gamma)$ merupakan matriks yang tidak grafikal, sehingga tidak terdapat graf realisasi untuk $A(\Gamma)$.

\section{KESIMPULAN}

Perkalian matriks pada graf adalah perkalian antara matriks ketetanggaan dari dua graf $G$ dan $H$ yang mempunyai himpunan simpul sama. Berdasarkan hasil penelitian diperoleh $A\left(W_{n}\right) A\left(\overline{W_{n}}\right)$ dan $A\left(\overline{W_{n}}\right) A(G)$ tidak grafikal apabila $n \geq 4$, dengan $\overline{W_{n}}$ merupakan komplemen graf roda dan graf $G$ merupakan subgraf roda yang diperoleh dengan cara menghapus sisi yang tidak bersisian dengan simpul pusat. Selanjutnya diperoleh $A\left(W_{n}\right) A(H)$ tidak grafikal dan $A\left(\overline{W_{n}}\right) A(H)$ tidak grafikal apabila $n \geq 6$, dengan graf $H$ merupakan subgraf roda yang diperoleh dengan cara menghapus sisi yang bersisian dengan simpul pusat.

\section{DAFTAR PUSTAKA}

[1] Munir, R. Matematika Diskrit. Ed ke-3. Informatika. Bandung. 2010.

[2] Prasad, K.M, Sudhakara, M, Sujatha, H.S dan Vinay, M. Matrix Product of Graphs. Combinatorial Matrix Theory and Generalized Inverses of Matrices. 2013; 1-16.

[3] Ferdias, P, Wamiliana. Representasi Matriks Graf Cut-Set dan Sirkuit. Seminar Nasional Matematika dan Pendidikan Matematika. 2011; 139-147.

NOVITA INDAH SAPUTRI : Jurusan Matematika FMIPA UNTAN, Pontianak vitaindahcx@gmail.com

MARIATUL KIFTIAH $\quad$ : Jurusan Matematika FMIPA UNTAN, Pontianak kiftiahmariatul@math.untan.ac.id

FRANSISKUS FRAN : : Jurusan Matematika FMIPA UNTAN, Pontianak fransiskusfran@math.untan.ac.id 